\title{
Anti-Inflammatory Activity of a Novel Family of Aryl Ureas Compounds in an Endotoxin-Induced Airway Epithelial Cell Injury Model
}

\author{
Nuria E. Cabrera-Benitez ${ }^{1,2}$, Eduardo Pérez-Roth ${ }^{3}$, Milena Casula ${ }^{1,2}$, Ángela Ramos-Nuez ${ }^{1,2}$, Carla Ríos- \\ Luci $^{3}$, Carlos Rodríguez-Gallego ${ }^{4}$, Ithaisa Sologuren ${ }^{4}$, Virginija Jakubkiene ${ }^{5}$, Arthur S. Slutsky ${ }^{6,7}$, \\ José M. Padrón ${ }^{3}$, Jesús Villar ${ }^{1,2,6 *}$
}

1 CIBER de Enfermedades Respiratorias, Instituto de Salud Carlos III, Madrid, Spain, 2 Multidisciplinary Organ Dysfunction Evaluation Research Network, Research Unit, Hospital Universitario Dr. Negrin, Las Palmas de Gran Canaria, Spain, 3 BioLab, Instituto Universitario de Bio-Orgánica "Antonio González" (IUBO-AG), Universidad de La Laguna, La Laguna, Spain, 4 Department of Immunology, Hospital Universitario Dr. Negrin, Las Palmas de Gran Canaria, Spain, 5 Department of Organic Chemistry, Faculty of Chemistry, Vilnius University, Vilnius, Lithuania, $\mathbf{6}$ Keenan Research Center at the Li Ka Shing Knowledge Institute of St. Michael's Hospital, Toronto, Canada, 7 Interdepartmental Division of Critical Care Medicine, University of Toronto, Toronto, Canada

\begin{abstract}
Background: Despite our increased understanding of the mechanisms involved in acute lung injury (ALI) and the acute respiratory distress syndrome (ARDS), there is no specific pharmacological treatment of proven benefit. We used a novel screening methodology to examine potential anti-inflammatory effects of a small structure-focused library of synthetic carbamate and urea derivatives in a well established cell model of lipopolysaccharide (LPS)-induced ALI/ARDS.

Methodology/Principal Findings: After a pilot study to develop an in vitro LPS-induced airway epithelial cell injury model, a library of synthetic carbamate and urea derivates was screened against representative panels of human solid tumor cell lines and bacterial and fungal strains. Molecules that were non-cytotoxic and were inactive in terms of antiproliferative and antimicrobial activities were selected to study the effects on LPS-induced inflammatory response in an in vitro cell culture model using A549 human alveolar and BEAS-2B human bronchial cells. These cells were exposed for $18 \mathrm{~h}$ to LPS obtained from Escherichia coli, either alone or in combination with the test compounds. The LPS antagonists rhein and emodin were used as reference compounds. The most active compound (CKT0103) was selected as the lead compound and the impact of CKT0103 on pro-inflammatory IL-6 and IL-8 cytokine levels, expression of toll-like receptor-4 (TLR4) and nuclear factor kappa $B$ inhibitor alpha $(\mathrm{I} K \mathrm{~B} \alpha)$ was measured. CKT0103 significantly inhibited the synthesis and release of IL- 6 and IL- 8 induced by LPS. This suppression was associated with inhibition of TLR4 up-regulation and I $\mathrm{KB} \alpha$ down-regulation. Immunocytochemical staining for TLR4 and $\mathrm{I} \mathrm{K} \alpha \alpha$ supported these findings.
\end{abstract}

Conclusions/Significance: Using a novel screening methodology, we identified a compound - CKT0103 - with potent antiinflammatory effects. These findings suggest that CKT0103 is a potential target for the treatment of the acute phase of sepsis and sepsis-induced ALI/ARDS.

Citation: Cabrera-Benitez NE, Pérez-Roth E, Casula M, Ramos-Nuez Á, Ríos-Luci C, et al. (2012) Anti-Inflammatory Activity of a Novel Family of Aryl Ureas Compounds in an Endotoxin-Induced Airway Epithelial Cell Injury Model. PLoS ONE 7(11): e48468. doi:10.1371/journal.pone.0048468

Editor: Rory Edward Morty, University of Giessen Lung Center, Germany

Received April 9, 2012; Accepted September 25, 2012; Published November 8, 2012

Copyright: (C) 2012 Cabrera-Benitez et al. This is an open-access article distributed under the terms of the Creative Commons Attribution License, which permits unrestricted use, distribution, and reproduction in any medium, provided the original author and source are credited.

Funding: This work was supported by grants from CIBER de Enfermedades Respiratorias, Instituto de Salud Carlos III, Spain (CB06/06/1088), Ministry of Science of Spain (CTQ2008-06806-C02-01/BQU); Ministry of Health, Spain (RTICC RD06/0020/1046); ACIISI, Canary Islands, Spain (PI 2007/021); FUNCIS (PI 43/09). EPR holds a "Sara Borrel" contract from Instituto de Salud Carlos III, Spain. The funders had no role in study design, data collection and analysis, decision to publish, or preparation of the manuscript.

Competing Interests: JV, JMP, NC, MC, AR, the CIBER de Enfermedades Respiratorias, the Canary Health Service, and the University of La Laguna have filed a patent application related to the use of CKT0103 in sepsis and sepsis-induced ALI. There are no further patents, products in development or marketed products to declare. This does not alter the authors' adherence to all the PLOS ONE policies on sharing data and materials. The rest of authors have not any conflict of interest to declare.

*E-mail: jesus.villar54@gmail.com

\section{Introduction}

Acute lung injury (ALI) and its more severe form, the acute respiratory distress syndrome (ARDS), is a relatively common syndrome in critically ill patients associated with high morbidity and mortality [1]. Data from the ALIVE Study [2] showed that about $7 \%$ of all intensive care unit patients develop ALI/ARDS, and that sepsis is the most common predisposing factor. Sepsis is characterized by a systemic inflammatory state in response to circulating microbes or microbial toxins such as lipopolysaccharide (LPS) or bacterial DNA [3]. The ultimate cause of death in septic patients is usually development of multiple system organ failure, which frequently starts as lung dysfunction $[1,4]$.

LPS, also termed endotoxin, is the major component of the outer membrane of gram-negative bacteria and is a common trigger of sepsis [5]. Toll-like receptors (TLRs), which function as 
sensors of microbial infection, recognize LPS and are critical for the initiation of inflammatory and immune defense responses [6]. A major downstream effect of TLR signaling is activation of the transcription nuclear factor kappa B $(\mathrm{NF}-\kappa \mathrm{B})$, which eventually leads to expression of many genes related to innate immunity and inflammation, and other gene products [6-8].

Despite intense research and an increased understanding of the pathophysiological processes involved, there are no specific pharmacological treatments of proven benefit for ALI/ARDS $[9,10]$. One approach for identifying novel therapies for various diseases is to use large scale screening of various molecules with appropriate simple models. Using a screening strategy based on a well established protocol of the National Cancer Institute (NCI) of the United States [11], we have previously identified targets that are active in various forms of cancer $[12,13]$. We wondered whether a similar screening program would be able to identify novel candidate molecules which might be effective in attenuating or inhibiting the inflammatory response which ultimately lead to LPS/sepsis-induced ALI/ARDS.

Using an in vitro LPS-induced pulmonary epithelial injury model based on the first steps in the development of sepsis/ALI [14-20], we screened a library of about 300 small molecules possessing a wide diversity of chemical structures, and identified a group of novel pyrimidinyl carbamates and pyrimidinyl ureas as potential therapeutic candidates in sepsis/ALI. These carbamates and ureas can be synthesized from the corresponding (pyrimidin-4-yloxy)and (pyrimidin-3-yl)-acetohydrazides, as reported previously [21]. The most active compound (CKT0103) was selected as the lead compound and further used to investigate the capacity of pharmacological inhibition of TLR4 signaling in LPS-stimulated human A549 alveolar and BEAS-2B bronchial pulmonary epithelial cells.

\section{Materials and Methods}

\section{Reagents}

All chemicals used in this study were commercially available and research-grade. File S1 for reagent details. To the best of our knowledge, there is no standard drug to be used as a reference in the treatment of LPS-induced effects. Hence, we selected rhein and emodin as reference compounds for our experimental study since both compounds are commercially available natural products from traditional herbs that have been shown to inhibit LPS-induced NF- $\kappa \mathrm{B}$ activation and inflammatory cytokine expression [22]. A subset from our library of 2,000 compounds was selected for this study; the only requisite was that the compounds to be studied were non-cytotoxic and non-antimicrobial (see ESM, for details).

\section{LPS-induced airway epithelial cell injury models}

We chose A549 cells [human pulmonary alveolar epithelial carcinoma cells (ATCG, Manassas, VA, USA)] and BEAS-2B cells [human bronchial epithelial cells (ATCG, Manassas, VA, USA)], as representative airway epithelial cell lines [14] to study the effects of the synthetic derivatives on the ability to inhibit LPS-induced effects in the airway epithelium These cells have been extensively used to study LPS-induced activation of pro-inflammtory cytokines, as an in vitro model based on the first steps in the development of sepsis-induced ALI/ARDS [14-20,23]. A549 and BEAS-2B cells were cultured as previously described, maintained in $75 \mathrm{~cm}^{2}$ flasks in DMEM and DMEN/F-12, respectively, supplemented with $10 \% \mathrm{FBS}$, in a $37^{\circ} \mathrm{C}, 5 \% \mathrm{CO}_{2}, 95 \%$ humidified air incubator.
Exponentially growing A549 and BEAS-2B cells were trypsinized and re-suspended in 2\% FBS antibiotic containing medium (100 units penicillin $\mathrm{G}$ and $0.1 \mathrm{mg}$ of streptomycin per $\mathrm{mL}$ ). Single cell suspensions displaying $>97 \%$ viability, by using the trypan blue dye exclusion method according to the standard protocol [24], were subsequently counted. After counting, dilutions were made to give the appropriate cell densities for inoculation onto 96well microtiter plates. Ciells were inoculated in a volume of $100 \mu \mathrm{L}$ per well at a density of $3 \times 10^{4}$ cells per well. After $24 \mathrm{~h}$, cells were exposed to Escherichia coli (E. coli) LPS $(0.1,1.0,10,100 \mathrm{ng} / \mathrm{mL})$ for 6, 12, and 18 hours. LPS was obtained from E. coli serotype 055:B5 (Sigma-Aldrich, St Louis, MO, USA). In our preliminary studies, A549 and BEAS-2B cell survival decreased with increasing concentration of $E$. coli LPS. The lowest survival was observed with $100 \mathrm{ng} / \mathrm{mL}$ of LPS during 18 hours. This LPS concentration and time-period were used for the subsequent experiments (see ESM and Figure S1 for details).

\section{Screening methodology to test the inhibition of LPS effects}

A549 and BEAS-2B cells were grown in 96-well microtiter plates in a volume of $100 \mu \mathrm{L}$ per well at a density of $3 \times 10^{4}$ cells per well. After $24 \mathrm{~h}$, cells were exposed to $100 \mathrm{ng} / \mathrm{mL}$ LPS for 18 hours either alone or in combination with each test or reference drug at a final concentration of $10 \mu \mathrm{M}$. This concentration was chosen based on preliminary antiproliferative assays. We tested 11 synthetic compounds (see ESM for details). Since the best results in terms of cell survival were observed for the derivative $2 \mathrm{e}$ (CKT0103), this compound was selected for further testing in our cell lines (see ESM and Table S1 for details).

Additionally, we tested: (i) LPS (100 ng/mL) either alone or in combination with $0.1,1,10,100$, and $1000 \mu \mathrm{M}$ CKT0103, and (ii) LPS $(100 \mathrm{ng} / \mathrm{mL})$ either alone or in combination with $0,5,10$, $20 \mu \mathrm{M}$ CKT0103. Tested compound was non-toxic to cells at a dose of $100 \mathrm{ng} / \mathrm{mL}$ E. coli LPS and $10 \mu \mathrm{M}$ CKT0103. For all experimental conditions and after incubation for $18 \mathrm{~h}$, cells were precipitated with $25 \mu \mathrm{L}$ ice-cold TCA $(50 \%$ w/v) and fixed for $60 \mathrm{~min}$ at $4^{\circ} \mathrm{C}$. Then, the sulforhodamine $\mathrm{B}$ (SRB) assay [25] was performed. The optical density $(\mathrm{OD})$ of each well was measured at 492 nm, using BioTek's PowerWave XS Absorbance Microplate Reader. The percentage of surviving cells (PS) was calculated for each dose as: $\mathrm{PS}=100 \times\left[\left(T_{D}-T_{L P S}\right) /\left(C-T_{L P S}\right)\right]$, where $T_{D}$ represents the OD of wells treated with the drug at drug dose $\mathrm{D}, C$ stands for the OD of untreated cell wells (negative control-vehicle), and $T_{L P S}$ corresponds to the OD of wells of cells treated only with LPS (positive control). With this calculation, a PS value of 0 corresponds to the effect of treating cells with LPS alone, while positive PS values denote net cell survival. Negative PS values represent either cytotoxicity of the tested compound, or a synergistic interaction with LPS.

\section{Assessment of A549 and BEAS-2B cell viability}

The viability of A549 and BEAS-2B cells was measured performing a dose-response curve of $0.1,1,10,100,1000 \mu \mathrm{M}$ CKT0103 with $100 \mathrm{ng} / \mathrm{mL}$ E. coli LPS using the trypan blue exclusion method [24] (see ESM and Figure S2 for details).

\section{Analysis of changes in cell morphology}

A549 and BEAS-2B cells were suspended at $5 \times 10^{6}$ cells/flask and inoculated in $75 \mathrm{~cm}^{2}$ flasks for $24 \mathrm{~h}$. Cells were then exposed to LPS $(100 \mathrm{ng} / \mathrm{mL})$ either alone or in combination with $10 \mu \mathrm{M}$ rhein, emodin or the lead compound CKT0103 (Table S1). Then, cells were examined and photographed (Olympus Camedia digital 
camera, $\times 400$ objective) under a phase-contrast microscope (Olympus CK-40 F-200) at the end of compound exposure.

\section{Measurement of Cytokines levels}

We measured IL-6 and IL-8 cytokine levels in the cell culture media collected from A549 and BEAS-2 cells by enzyme-linked immunosorbent assay (ELISA) following standard techniques. After $18 \mathrm{~h}$ of drug incubation, media from each well were collected and stored at $-80^{\circ} \mathrm{C}$. Quantitative human IL-6 and IL-8 levels were measured using a flow cytometry-based bead array system in a FACS Calibur flow cytometer, and analyzed with CellQuest Pro software according to the manufacturer's protocols (BD Biosciences. San Jose, CA, USA). The results were expressed as picograms of released cytokine $/ 10^{6}$ adherent cells (pg/106 cells). The theoretical limit of detection for each protein using the BD CBA Human Inflammatory Cytokines Kit is defined as the corresponding concentration at two standard deviations above the median fluorescence of 20 replicates of the negative control (0 pg/ $\mathrm{mL})$.

\section{Protein Extraction and Immunoblotting}

After $18 \mathrm{~h}$ of compound incubation, A549 and BEAS-2B cells from each experimental group were harvested and centrifuged at $1200 \mathrm{rpm}$ for 7 minutes. Cell pellets were re-suspended in a cold lysis buffer ( $1 \%$ Nonidet P-40, $25 \mathrm{mM}$ Tris-HCl (pH 7.5), $150 \mathrm{mM}$ sodium chloride, $1 \mathrm{mM}$ EDTA, $5 \mathrm{mM}$ sodium fluoride, $1 \mathrm{mM}$ sodium orthovanadate, $1 \mathrm{mM}$ phenylmethylsulfonyl fluoride) plus Protease Inhibitor Cocktail and incubated for $10 \mathrm{~min}$ on ice. The supernatant, containing predominantly total proteins, was collected after $5 \mathrm{~min}$ centrifugation at $14,000 \mathrm{rpm}$ at $4^{\circ} \mathrm{C}$. Protein concentrations were determined with the Bio-Rad DC protein assay.

For immunoblotting, each sample was reduced in SDS-PAGE loading buffer prior to being boiled and then separated by SDSPAGE $(10 \%)$ and visualized by colloidal Coomassie staining. After this, samples were electroblotted onto polyvinylidene difluoride (PVDF) membrane, blocked for $1 \mathrm{~h}$ at room temperature in $5 \%$ non-fat milk, and probed with anti-TLR4 and anti-IкB $\alpha$ antibodies (Santa Cruz Biotechnology, Santa Cruz, CA). Following incubation with the corresponding peroxidase-conjugated secondary antibody (Goat Anti-rabbit IgG-HRP; Santa Cruz Biotechnology, Santa Cruz, CA), immunoblots were stripped using Restore Western Blot Stripping Buffer for $15 \mathrm{~min}$ at room temperature and re-probed with an anti- $\beta$-actin (Cell Signaling Technology, MA) antibody. Chemiluminiscence detection was performed with the ECL kit. Densitometry was performed using Scion Image software package. Western blots were repeated three times in each experimental condition.

\section{Immunocytochemistry for TLR4 and I $\mathrm{B} \alpha$}

Immunocytochemical stains were performed by applying a standard avidin-biotin complex (ABC) technique (see ESM for details). We used primary antibodies directed against TLR4 and $\mathrm{I} \kappa \mathrm{B} \alpha$ (Santa Cruz Biotechnology Inc, Santa Cruz, CA). Staining was visualized using the 3-amino-9-ethylcarbazole $\mathrm{AEC}+$ /substrate Chromogen. Images were viewed using an Olympus (BX50) microscope and photographed with an Olympus Camedia digital camera at $\times 400$ magnifications.

\section{Statistical Analysis}

Data were expressed as mean \pm standard deviation $(\mathrm{SD})$ and analyzed using Graph Pad Prism version 5.0 software. Comparisons involving all experimental groups were performed with one- way analysis of variance (ANOVA). We used a Bonferroni correction for multiple comparisons. For Western blot experiments, the effects on TLR 4 and I $\kappa B \alpha$ were analyzed by the same statistical analyses using densitometric data normalized to $\beta$-actin as loading controls. Data are from three independent experiments. Data analyses were performed using SPSS (version 15.0 for Windows). Effects were considered to be statistically significant when $\mathrm{p}<0.05$.

\section{Results}

\section{Inhibition of LPS-induced effects}

Tested synthetic compounds diminished the effects induced by LPS. The percentages of cell survival (PS) values were in the range 9.42 to $58.72 \%$ in A549 cells and 7.25 to $59.96 \%$ in BEAS-2B cells (Figure 1, Table S1). In general, they represented an improvement to the reference compounds rhein and emodin. The best results were obtained for derivative 2e (CKT0103) (N-(2,4-dichlorophenyl)- $\mathrm{N}^{\prime}$ [(6-methyl-2,4-dioxo-1,2-dihydropyrimidin-3(4H)-yl) methyl]urea), with a PS value of $58.72 \%$ in A549 cells and $59.96 \%$ in BEAS-2B cells. With the exception of this compound, there were only small differences in the biological activity between carbamate $(\mathrm{la}-\mathrm{c})$ and urea $(2 \mathrm{a}-\mathrm{h})$ derivatives, and between electron donor and electron withdrawing substituents on the aromatic ring. Based on this result, CKT0103 was selected for further testing. CKT0103 (at a concentration of $10 \mu \mathrm{M})$ markedly inhibited LPS-induced effects in A549 and BEAS-2B cells (Figure 2).

\section{CKT0103 does not reduce A549 and BEAS-2B cell viability}

CKT0103 only had a significant effect on A549 and BEAS-2B cell viability at a concentration of $1000 \mu \mathrm{M}$ (Figure S2).

\section{Morphological changes}

Control-vehicle A549 and BEAS-2B cells incubated in the presence of vehicle- $0.5 \%(\mathrm{v} / \mathrm{v})$ DMSO grew as a monolayer with
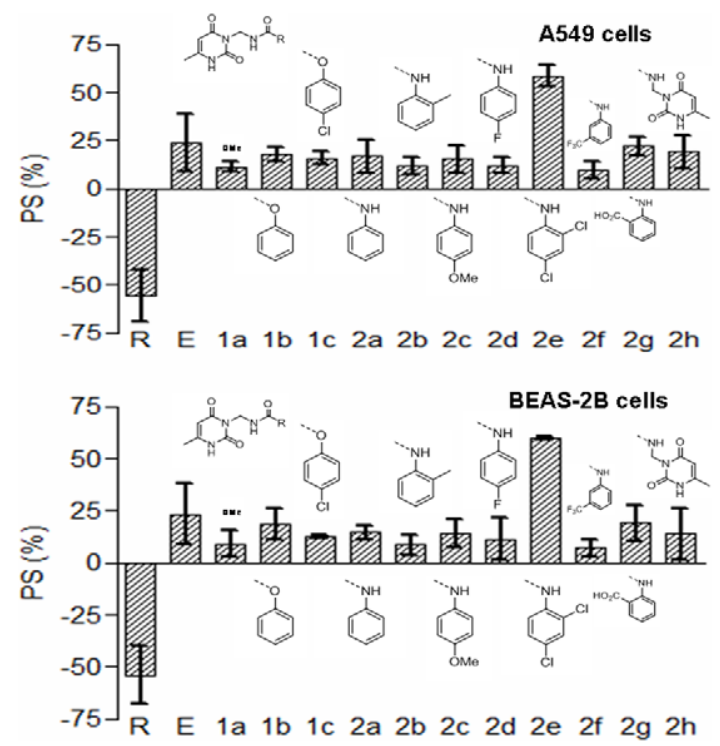

Figure 1. Percent of survival (PS) of $100 \mathrm{ng} / \mathrm{mL}$ LPS-stimulated $A 549$ and BEAS-2B cells in combination with $10 \mu \mathrm{M}$ rhein $(R)$, emodin (E), and the rest of synthetic products. 1a-c: pyrimidinyl carbamates; 2a-h: pyrimidinyl ureas for 18 hours. The chemical structures of the products under evaluation are shown. doi:10.1371/journal.pone.0048468.g001 

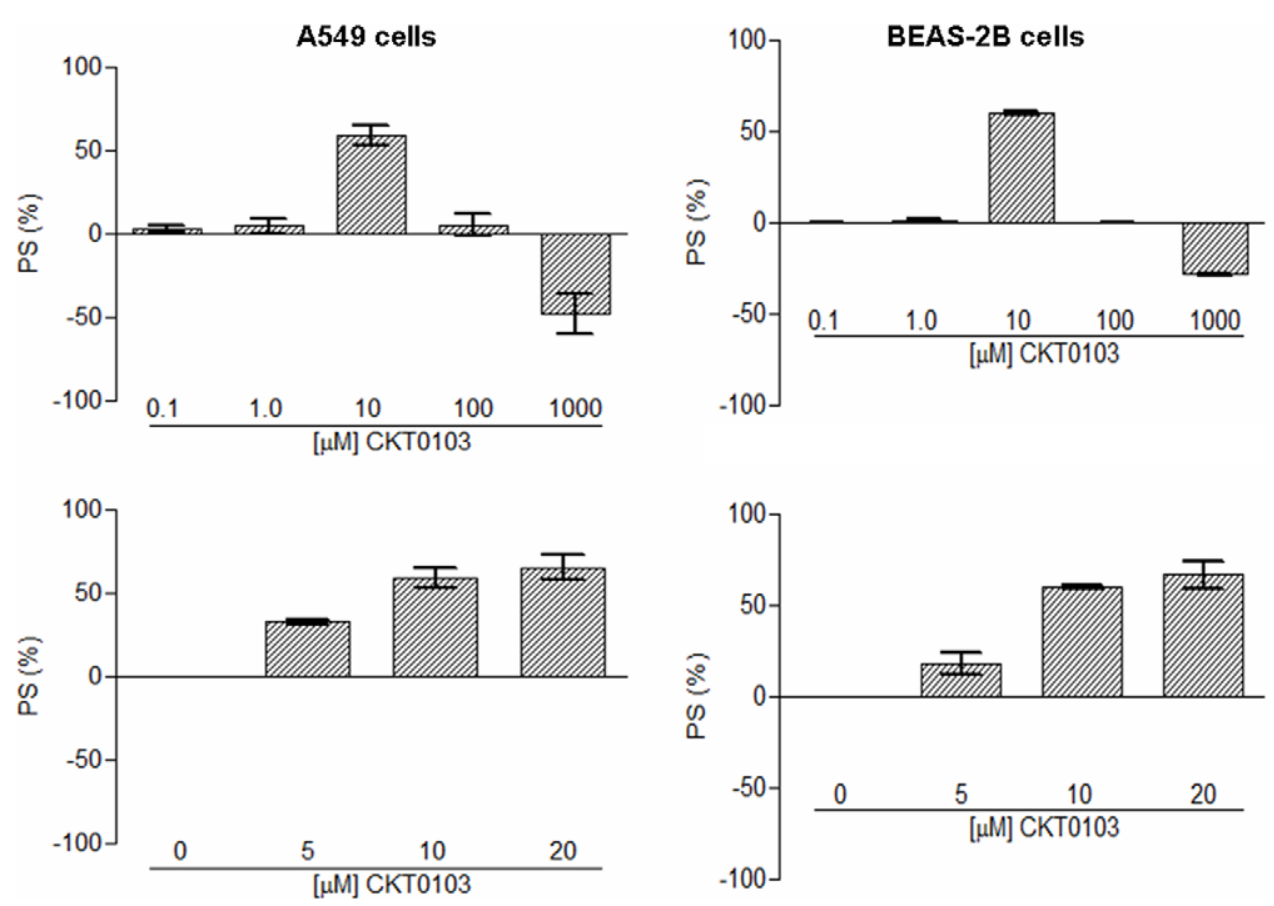

Figure 2. Percent of survival (PS) of $100 \mathrm{ng} / \mathrm{mL}$ LPS-stimulated A549 and BEAS-2B cells in combination with 0.1-1-10-100-1000 $\mu$ M CKT0103 or in combination with 0-5-10-20 $\mu \mathrm{M}$ CKT0103 for 18 hours. doi:10.1371/journal.pone.0048468.g002

individual cells having typical epithelial shape. After $18 \mathrm{~h}$ of $100 \mathrm{ng} / \mathrm{mL}$ E. coli LPS stimulation, A549 and BEAS-2B cells became less confluent, more rounded, and detached from the well. These changes were also observed in cells exposed to E. coli LPS plus rhein and emodin. When cells were treated with $100 \mathrm{ng} / \mathrm{mL}$ E. coli LPS plus $10 \mu \mathrm{M}$ CKT0103, cell detachment was prevented and a higher number of cell-cell contacts were observed (Figure 3).

Pro-inflammatory cytokine levels

The reference compounds and CKT0103 reduced IL-6 and IL8 levels induced by LPS alone in A549 and BEAS-2B cells $(\mathrm{p}<0.001$, Figure 4).
TLR4 and $\mathrm{I} \kappa \mathrm{B} \alpha$ protein levels

The expression of TLR4 was increased when A549 and BEAS2B cells were exposed to LPS $(\mathrm{p}<0.001)$ (Figure 5). Co-treatment with rhein and emodin prevented the increase in TLR4 levels in both cell lines. CKT0103 significantly reduced TLR4 levels $(\mathrm{p}<0.001)$; this effect was significantly greater than either LPS+rhein $(p<0.001)$ or LPS+emodin $(p<0.001)$. In addition, exposure to LPS resulted in the degradation of $I \kappa B \alpha$ in both cell lines $(\mathrm{p}<0.001)$; the decrease was markedly attenuated by CKT0103. Co-treatment with rhein or emodin did affect IкB $\alpha$ protein levels in a negative manner. However, CKT0103 produced a statistically significant increase of $I \kappa \mathrm{B} \alpha$ protein levels in A549 and BEAS-2B cells when compared to LPS ( $p<0.001$ and
C

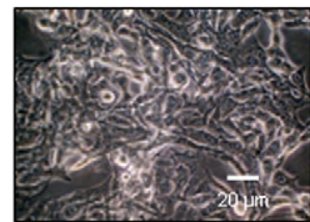

A549

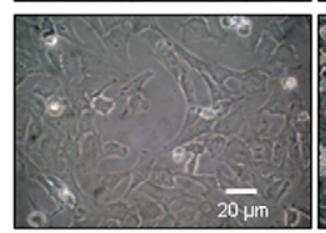

LPS
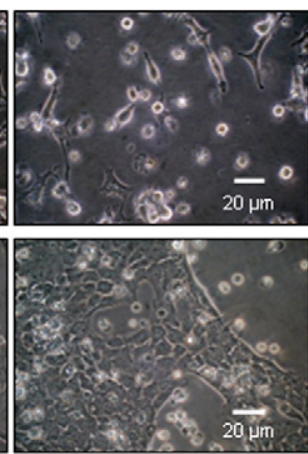

$\mathbf{R}$
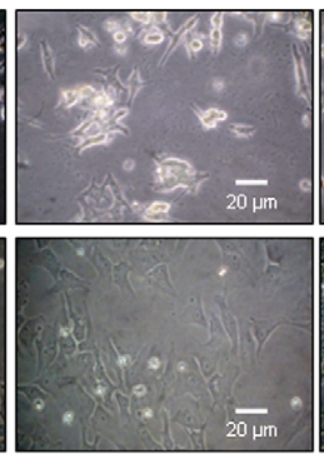

E

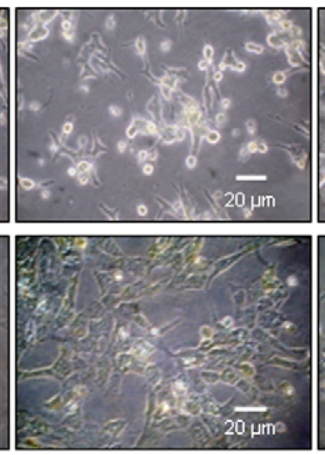

CKT0103

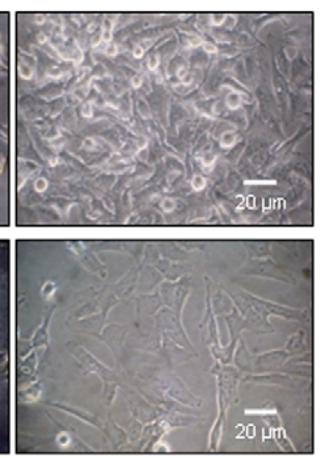

Figure 3. Morphological changes in A549 and BEAS-2B cells after treatment with $100 \mathrm{ng} / \mathrm{mL} E$. coli LPS either alone or in combination with $10 \mu \mathbf{M}$ rhein (R), emodin (E), CKT0103. We used A549 and BEAS-2B cells as control-vehicle (C) incubated in the presence of vehicle- $0.5 \%(\mathrm{v} / \mathrm{v})$ DMSO. $\times 400$ magnifications. doi:10.1371/journal.pone.0048468.g003 
A549 cells
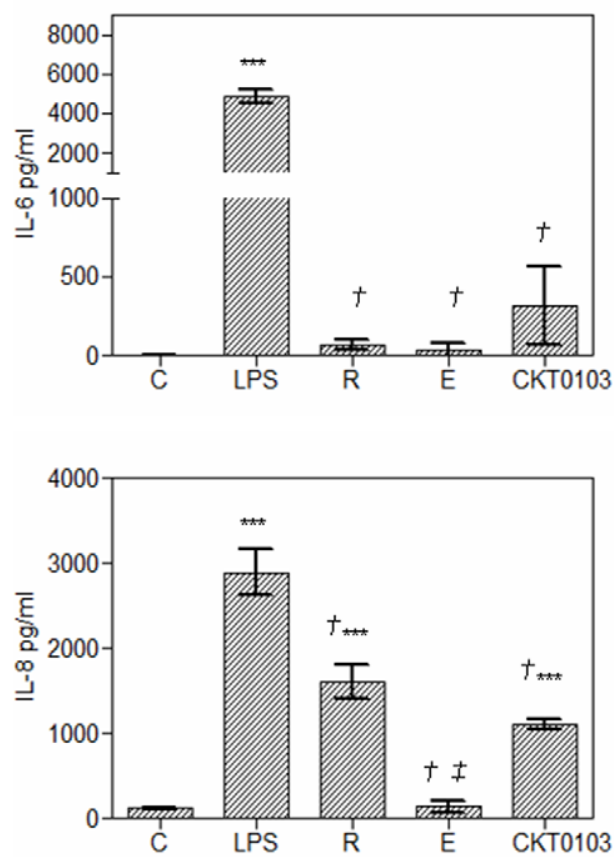

BEAS-2B cells
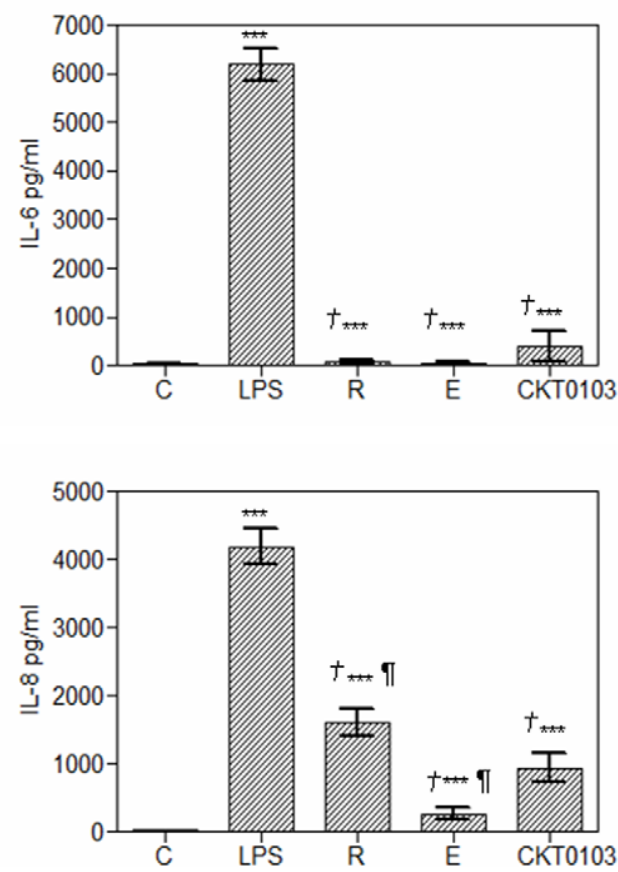

Figure 4. Pro-inflammatory IL-6 and IL-8 production by A549 and BEAS-2B cells as determined by CBA and flow cytometry analysis of culture supernatant after 18 hours of $100 \mathrm{ng} / \mathrm{mL} E$. coli LPS stimulation either alone or in combination with $10 \mu \mathrm{M}$ rhein, emodin and CKT0103. ${ }^{* * *} p<0.001$ vs. control-vehicle $(C) ; \uparrow p<0.001$ vs. LPS; $\uparrow p<0.05$ vs. LPS+ CKT0103; $\$ p<0.001$ vs. LPS $+C K T 0103$. doi:10.1371/journal.pone.0048468.g004

$\mathrm{p}<0.05$, respectively). Immunocytochemical staining for TLR4 and $\mathrm{I} \kappa \mathrm{B} \alpha$ supported these findings (Figure 6).

\section{Discussion}

A successful program aimed at discovering novel medicines requires reasonably reliable preclinical models. In anticancer drug chemotherapy, appropriate models have been developed [26], and this strategy has been applied for the past couple of decades by the NCI within the Development Therapeutics Program [11]. Based on this approach, we initiated a screening program to identify new candidate drugs directed at ALI/sepsis. In this study, we provide a reasonably rapid, simple, and reproducible method to screen novel anti-inflammatory compounds using an LPS-induced airway epithelium cell injury model. The main findings of this study are: (i) our screening approach was able to identify an interesting candidate; (ii) CKT0103, the candidate chosen inhibited LPSinduced effects in two in vitro models of endotoxin-induced airway epithelial cell injury; (iii) inhibition of cytokine secretion was associated with down-regulation of TLR4 and up-regulation of $\mathrm{I} \kappa \mathrm{B} \alpha$; and (iv) inhibition of LPS activity was achieved while cell viability and integrity was preserved during CKT0103 treatment.

We selected A549 and BEAS-2B cell lines as representative alveolar and bronchial epithelial cells; epithelial cells have been implicated in the pathogenesis of sepsis-induced ALI/ARDS [1417,19,20,23,27]. In histological sections from patients with ARDS, one of the first lesions appears to be alveolar epithelial damage [28], and one of the most important mechanisms that determines the severity of lung injury is the magnitude of injury to the alveolar epithelial barrier [1]. Epithelial cells generate various immune effectors such as cytokines, chemokines, and antimicrobial peptides in response to inflammatory stimuli $[23,29]$ and airway epithelium controls lung inflammation and injury through the NF- $\kappa \mathrm{B}[30]$. A plethora of experimental reports have used human A549 alveolar and BEAS-2B bronchial epithelial cell lines to study the acute lung inflammatory response induced by LPS, as acceptable, validated and suitable in vitro airway epithelial injury models based on the first steps in the development of sepsis and ALI/ARDS [14-20,23,27]. We selected E. coli LPS treatment because it has been used in most endotoxin-induced lung injury model $[7,8,31,32]$ and LPS is a key pathogen recognition molecule for sepsis [7,30] that induces apoptosis in lung cells [33]. Several previous reports evaluating the efficacy of compounds on the LPSinduced activation of proinflammatory cytokines in the lung have used a similar in vitro alveolar epithelial injury model with A549 cells [16] or prior to examining the in vivo anti-inflammatory effects [34].

Prior to screening of the compounds, we optimized our experimental conditions. For example, the amount of FBS in the culture medium had to be reduced to $2 \%$ in order to allow cell growth and to observe differences in effect between LPS-treated and untreated cells. To keep the method simple, test compounds were administered together with LPS and the exposure time set at $18 \mathrm{~h}$. Two controls were defined: one for untreated cells incubated in the presence of vehicle- $0.5 \%(\mathrm{v} / \mathrm{v})$ DMSO (negative control), and one for cells exposed to LPS (positive control). The effect was defined as percent of survival (PS), where the negative control has a PS value of $100 \%$ and the positive control has a value of $0 \%$. We also studied emodin and rhein as reference compounds. We selected these compounds since they are commercially available natural products present in traditional Chinese herbs, and have been shown to inhibit LPS-induced NF- $\kappa \mathrm{B}$ activation and cytokine expression [35,36]. They have been considered as potential candidates for the treatment of sepsis [22]. Based on this approach, we identified CKT0103 from a novel family of aryl 


\section{A549 cells}

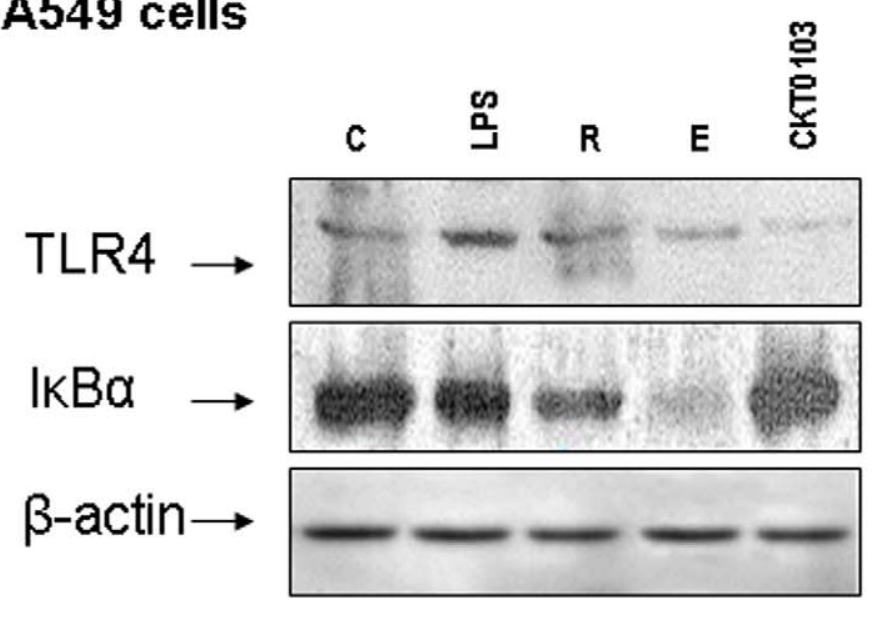

BEAS-2B cells

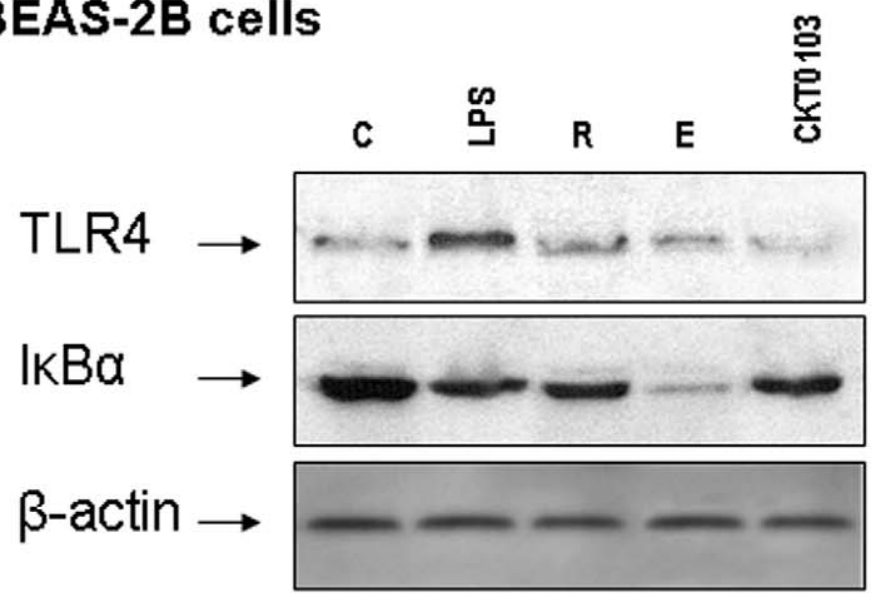

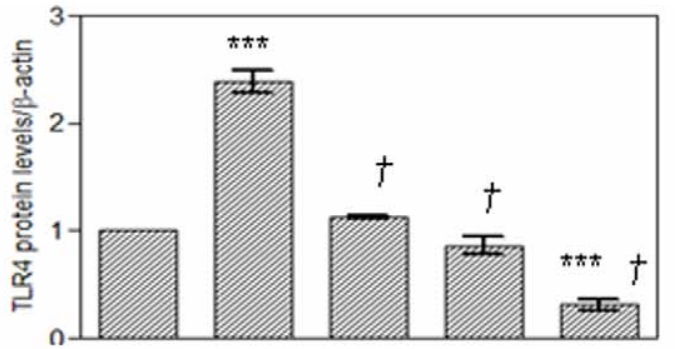
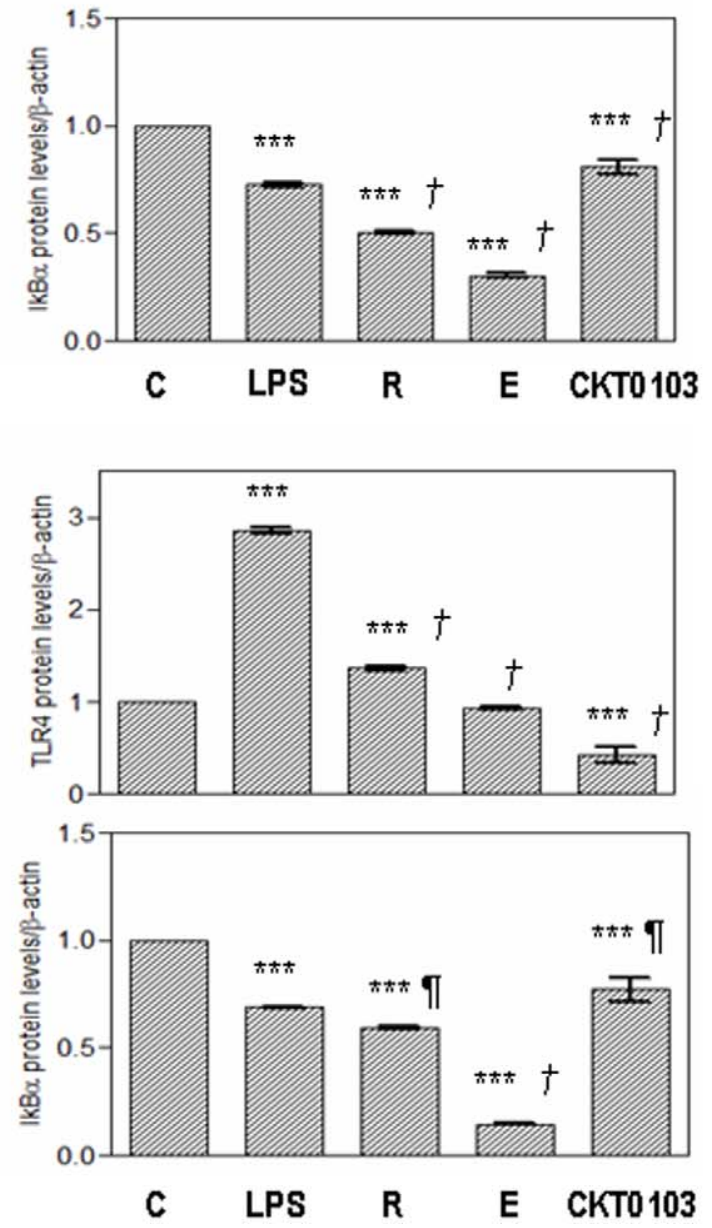

Figure 5. Immunobloting analysis for TLR4 and IKB $\alpha$ in A549 and BEAS-2B cells after stimulation with $100 \mathrm{ng} / \mathrm{mL}$ E. coli LPS either alone or in combination with $10 \mu \mathrm{M}$ rhein, emodin and CKT0103 for 18 hours. C: Control-vehicle group; LPS: A549 and BEAS-2B cells stimulated with $100 \mathrm{ng} / \mathrm{mL}$ E. coli LPS; R: A549 and BEAS-2B cells stimulated with $100 \mathrm{ng} / \mathrm{mL}$ E. coli LPS in combination with $10 \mu M$ rhein for 18 hours; E: A549 and BEAS-2B cells stimulated with $100 \mathrm{ng} / \mathrm{mL}$. coli LPS in combination with $10 \mu \mathrm{M}$ emodin for 18 hours; CKTO103: A549 and BEAS-2B cells stimulated with $100 \mathrm{ng} / \mathrm{mL}$ E. coli LPS in combination with $10 \mu \mathrm{M}$ CKT0103 for 18 hours. ${ }^{* * *} \mathrm{p}<0.001 \mathrm{vs}$. control-vehicle (C); $\uparrow \mathrm{p}<0.05$ vs. LPS; $\uparrow \mathrm{p}<0.001$ vs. LPS.

doi:10.1371/journal.pone.0048468.g005

carbamates and ureas, and further examined its impact using LPStreated cells.

Sepsis and sepsis-induced ALI/ARDS are significant causes of morbidity and mortality worldwide. Over $40 \%$ of patients with sepsis go on to develop ALI/ARDS. Various strategies for suppressing the inflammatory response have been tested in clinical trials for the treatment of sepsis. However, these trials have thus far been largely unsuccessful [37], and identification of novel therapeutic approaches for sepsis and/or endotoxin-induced ALI is an area of intense investigation. Since sepsis-induced ALI/ ARDS is both an infectious and an inflammatory process, studies have addressed therapeutic inhibition of inflammatory mediators
[38], direct neutralization of LPS [39] and antimicrobial peptides [40]. There are a number of studies addressing the antiinflammatory effects of new chemical compounds in the context of endotoxin-induced epithelial cell injury [41-44]; however, the mechanisms of action and indications are quite different than our compound.

TLR4, a member of the Toll-like receptor family, is expressed in airway epithelial cells [45] and has been shown to be the main upstream sensor for LPS in vitro and in vivo. Toll-like receptors play a central role in initiating the innate immune system and activating NF- $\kappa \mathrm{B}[6]$. Based on our previous animal studies [46,47] showing a potential therapeutic role for signaling events related to the 

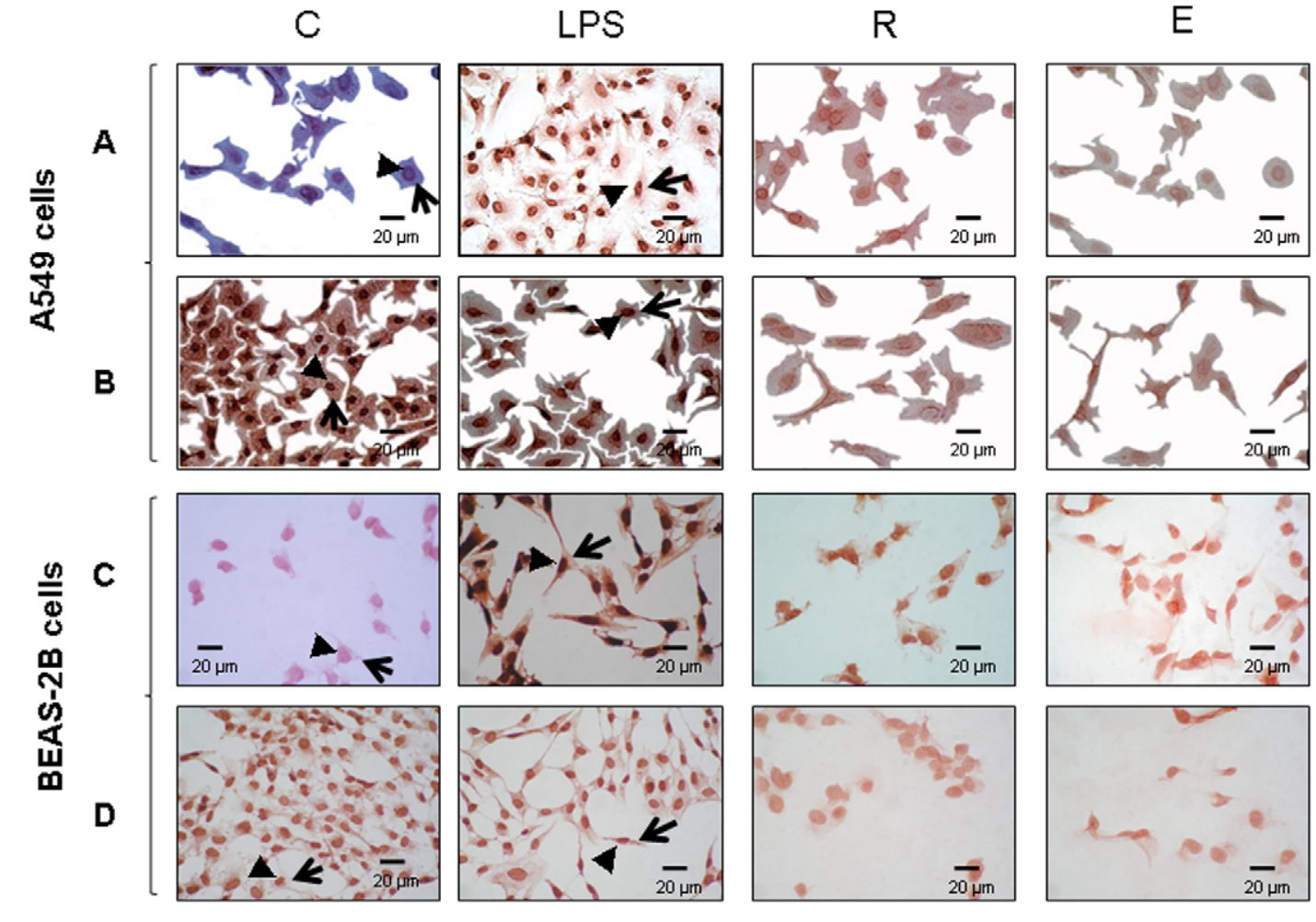

CKT0103
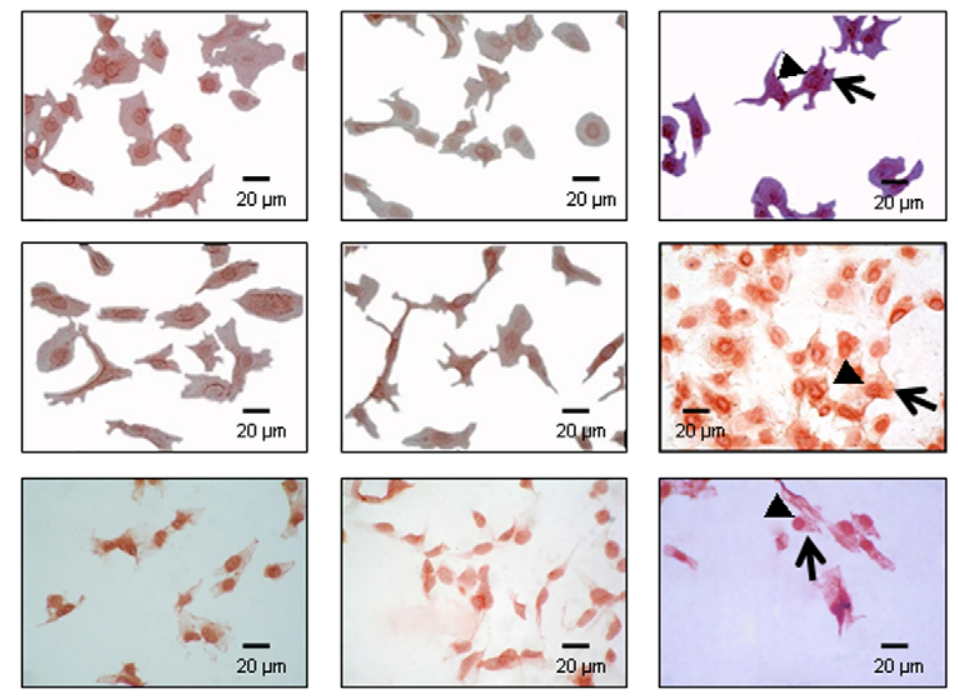

Figure 6. TLR4 $(A, C)$ and $I \kappa B \alpha(B, D)$ protein immunocytochemical stainings in A549 $(A, B)$ and BEAS-2B (C,D) cells stimulated with $100 \mathrm{ng} / \mathrm{mL}$ LPS (LPS) either in presence or absence of $10 \mu \mathrm{M}$ rhein (R), emodín (E), CKT0103 (CKT0103) for 18 hours. Red-pink color indicates positive staining (3-amino-9-ethylcarbazole) for TLR4 and I $\mathrm{K} \alpha$ proteins; blue/violet indicates nuclei counterstained with hematoxylin. TLR4 staining was found in nuclei (arrowheads) and cytoplasm (large arrows) in A549 and BEAS-2B cells treated with LPS but not in A549 and BEAS-2B control-vehicle cells or treated with LPS plus CKT0103. IKB $\alpha$ staining was found in nuclei (arrowheads) and cytoplasm (large arrows) in control-vehicle A549 and BEAS-2B cells and in A549 and BEAS-2B cells treated with LPS plus CKT0103. Strong immunostaining for TLR4 was observed in the LPS group and strong $1 \kappa B \alpha$ immunostaining was observed in control-vehicle A549 and BEAS-2B cells. Panels correspond to $\times 400$ magnifications. doi:10.1371/journal.pone.0048468.g006

TLR4/NF- $\kappa \mathrm{B}$ pathway, we pursued therapeutic targets induced by LPS-induced lung epithelial cell injury $[32,48]$. Since previous in vitro studies using LPS-stimulated airway epithelial cells focused on activation of proinflammatory mediators and increased cytokine release [14-20,39], we first examined the expression of proinflammatory cytokines IL-6 and IL-8. Elevated levels of these cytokines are found in patients with ARDS, and have been found to have a direct correlation with the severity of lung inflammation and mortality [49,50]. We found that CKT0103 down-regulated the expression of IL-8 induced by LPS activation. While rhein and emodin interfered with the IL-6 overproduction induced by LPS, CKT0103 suppressed the effects of LPS. This is a relevant finding since lung levels of chemokines are increased in ALI/ARDS patients and in experimental models of acute lung injury $[49,51,52]$ and levels of pulmonary pro-inflammatory cytokines correlate with mortality in experimental models of sepsis and in patients with sepsis-induced ALI/ARDS [49,53]. Epithelial NF$\kappa \mathrm{B}$ activation is sufficient to promote airway inflammation during ALI/ARDS $[54,55]$. NF- $\kappa \mathrm{B}$ activation is mediated by $\mathrm{I} \kappa \mathrm{B} \alpha$ degradation. We found that GKT0103 down-regulated TLR4, which inhibited down-regulation of $\mathrm{I} \kappa \mathrm{B} \alpha$ induced by LPS. However, we cannot exclude the possibility that the activation of a TLR4-independent mechanism would induce pro-inflammatory cytokines.

In summary, we have described a fast, simple and reliable cell culture method to screen compounds as potential inhibitors of LPS-induced airway epithelial cell injury. A new family of LPS inhibitors was discovered from a subset of our library of natural and synthetic compounds. This approach identified a potential therapeutic role for CKT0103 which inhibited cytokine secretion as a result of down-regulation of TLR 4 and up-regulation of I $\mathrm{B} \alpha$ in A549 alveolar cells and BEAS-2B bronchial cells. Although the urea derivative CKT0103 had a marked effect on LPS-induced inflammatory activity, the precise mechanism of action requires further studies. Such studies could include: LPS-binding studies, interference with several steps of the TLR $4 / \mathrm{NF}-\kappa \mathrm{B}$ pathway, and an examination of their effects on in vivo model of sepsis-induced ALI/ARDS.

In conclusion, we have demonstrated that CKT0103, a novel compound from a family of aryl ureas, counteracted the proinflammatory activity of LPS by modulating the TLR4/NF- $\kappa \mathrm{B}$ pathway in two in vitro LPS-induced airway epithelial cell injury models based on the first steps of the development of sepsis/ALI. These studies suggest that CKT0103 could be a potential therapy in the acute phase of sepsis and septic ALI/ARDS. These findings provide a basis for testing this novel compound in animal models of sepsis-induced acute lung injury.

\section{Supporting Information}

Table S1 Chemical structure of natural and synthetic compounds and percentage of survival (PS) of A549 and BEAS-2B cells stimulated with $100 \mathrm{ng} / \mathrm{mL} E$. coli $L P S$ in combination with: $1 \mathrm{a}-\mathrm{c}$ : pyrimidinyl carbamates; $2 \mathrm{a}-\mathrm{h}$ : pyrimidinyl ureas; $R=$ chemical structure.

(DOG) 
Figure S1 Survival curves of A549 and BEAS-2B cells after 6, 12 and 18 hours of 0.1-1.0-10-100 ng/mL $E$. coli LPS stimulation. We used A549 and BEAS-2B cells as controlvehicle $(\mathrm{C})$ cells incubated in the presence of vehicle- $0.5 \%(\mathrm{v} / \mathrm{v})$ DMSO. The values reported for E. coli LPS concentrations have been normalized to those for untreated (no LPS) control-vehicle cells. ***p $<0.001$ vs. control.

(TIF)

Figure S2 Trypan blue exclusion assay. The percentage of viable and non-viable cells in A549 and BEAS-2B cell populations after treatment with $100 \mathrm{ng} / \mathrm{mL} E$. coli LPS in the presence or absence of different concentrations of CKT0103 (0-0.1-1-10-100$1000 \mu \mathrm{M})$ for 18 hours. ${ }^{* * *} \mathrm{p}<0.001$ vs. control $(\mathrm{C}) ; \uparrow \mathrm{p}<0.001$ vs. LPS.

(TIF)

\section{References}

1. Ware LB, Matthay MA (2000) The acute respiratory distress syndrome. N Engl J Med 342: 1334-1349.

2. Brun-Buisson G, Minelli C, Bertolini G, Brazzi L, Pimentel J, et al (2004) Epidemiology and outcome of acute lung injury in European intensive care units. Results from the ALIVE study. Intensive Care Med 30: 51-61.

3. Vincent JL, Sun Q Dubois MJ (2002) Clinical trials of immunomodulatory therapies in severe sepsis and septic shock. Clin Infect Dis 34: 1084-1093.

4. Angus DC, Linde-Zwirble WT, Lidicker J, Clermont G, Carcillo J, et al (2001) Epidemiology of severe sepsis in the United States: analysis of incidence, outcome, and associated costs of care. Crit Care Med 29: 1303-1310.

5. Sparwasser T, Miethke T, Lipford G, Borschert K, Hacker H, et al (1997) Bacterial DNA causes septic shock. Nature 386: 336-337.

6. Fan J, Ye RD, Malik AB (2001) Transcriptional mechanisms of acute lung injury. Am J Physiol Lung Cell Mol Physiol 281: L1037-1050.

7. Lin WJ, Yeh WC (2005) Implication of Toll-like receptor and tumor necrosis factor alpha signaling in septic shock. Shock 24: 206-209.

8. Ma SF, Grigoryev DN, Taylor AD, Nonas S, Sammani S, et al (2005) Bioinformatic identification of novel early stress response genes in rodent models of lung injury. Am J Physiol Lung Cell Mol Physiol 289: L468-L477.

9. Zeiher BG, Artigas A, Vincent JL, Dmitrienko A, Jackson K, et al (2004) Neutrophil elastase inhibition in acute lung injury: results of the STRIVE study. Critical Care Med 32: 1695-1702.

10. Matthay MA, Brower RG, Carson S, Douglas IS, Eisner M, et al (2011) Randomized, placebo-controlled clinical trial of an aerosolized beta-agonist for treatment of acute lung injury. Am J Respir Crit Care Med 184: 561-568.

11. Shoemaker RH (2006) The NCI60 human tumour cell line anticancer drug screen. Nat Rev Cancer 6: 813-823.

12. Leon LG, Rios-Luci C, Tejedor D, Perez-Roth E, Montero JC, et al (2010) Mitotic arrest induced by a novel family of DNA topoisomerase II inhibitors. J Med Chem 53: 3835-3839.

13. Leon LG, Carballo RM, Vega-Hernandez MC, Miranda PO, Martin VS, et al (2008) Beta-hydroxy-alpha,beta-unsaturated ketones: A new pharmacophore for the design of anticancer drugs. Part 2. ChemMedChem 3: 1740-1747.

14. Koyama S, Sato E, Nomura H, Kubo K, Miura M, et al (1999) The potential of various lipopolysaccharides to release monocyte chemotactic activity from lung epithelial cells and fibroblasts. Eur Respir J 14: 545-552.

15. MacRedmond R, Singhera GK, Dorscheid DR (2009) Erythropoietin inhibits respiratory epithelial cell apoptosis in a model of acute lung injury. Eur Respir J 33: $1403-1414$.

16. Liaudet L, Mabley JG, Pacher P, Virág L, Soriano FG, et al (2002) Inosine exerts a broad range of antiinflammatory effects in a murine model of acute lung injury. Ann Surg 235: 568-578.

17. Yeh CH, Cho W, So EC, Chu CC, Lin MC, et al (2011) Propofol inhibits lipopolysaccharide-induced lung epithelial cell injury by reducing hypoxiainducible factor-1alpha. Br J Anaesth 106: 590-599.

18. Wang YL, Malik AB, Sun Y, Hu S, Reynolds AB, et al (2011) Innate immune function of a dherens junction protein p120-catenin in endothelial response to endotoxin. J Immunol 186: 3180-3187.

19. Muroya M, Chang K, Uchida K, Bougaki M, Yamada Y (2012) Analysis of cytotoxicity induced by proinflammatory cytokines in the human alveolar epithelial cell line A549. Biosci Trends 6: 70-80.

20. Boots AW, Gerloff K, Bartholomé R, van Berlo D, Ledermann K, et al (2012) Neutrophils augment LPS-mediated pro-inflammatory signaling in human lung epithelial cells. Biochim Biophys Acta 1823: 1151-1162.

21. Jakubkiene V KZ, Barbuliene MM, Vainilavicius P (2010) Synthesis of (pyrimidin4-yloxy)-and (pyrimidin-3-yl)acetyl azides and their rearrangement to carbamates and ureas. Arkivoc 11: 39-48.

22. Liu X, Cheng J, Zheng X, Chen Y, Wu C, et al (2009) Targeting CpG DNA to screen and isolate anti-sepsis fraction and monomers from traditional Chinese herbs using affinity biosensor technology. Int Immunopharmacol 9: 1021-1031.
File S1

(DOC)

\section{Author Contributions}

Conceived and designed the experiments: JV JMP MG NG. Performed the experiments: MC NC AR GR EP CR VJ JMP IS. Analyzed the data: JV JMP MC NC ASS IS. Contributed reagents/materials/analysis tools: JV JMP NC CRG VJ. Wrote the paper: JV MC NC ASS JMP. Coordinated data collection and data quality: JV JMP MC NC AR ASS. Contributed substantially to the analysis and interpretation of data, provided critical revision of the article, and provided final approval of the version to be published: JV JMP NC EP ASS. Obtained funding for the study: JV JMP. Participated in the writing process of the manuscript and read and approved the final manuscript: NC EP MC AR CRG IS VJ ASS JMP JV.

23. Larsson BM, Larsson K, Malmberg P, Palmberg L (1999) Gram positive bacteria induce IL-6 and IL-8 production in human alveolar macrophages and epithelial cells. Inflammation 23: 217-230.

24. Strober W (2001) Trypan blue exclusion test of cell viability. Curr Protoc Immunol Appendix 3: Appendix 3B.

25. Skehan P, Storeng R, Scudiero D, Monks A, McMahon J, et al (1990) New colorimetric cytotoxicity assay for anticancer-drug screening. J Natl Cancer Inst 82: $1107-1112$

26. Shoemaker RH, Scudiero DA, Melillo G, Currens MJ, Monks AP, et al (2002) Application of high-throughput, molecular-targeted screening to anticancer drug discovery. Curr Top Med Chem 2: 229-246.

27. Charles PE, Tissières P, Barbar SD, Croisier D, Dufour J, et al (2011) Mildstretch mechanical ventilation upregulates toll-like receptor 2 and sensitizes the lung to bacterial lipopeptide. Crit Care 15: R181.

28. Bachofen M, Weibel ER (1997) Alterations of the gas exchange apparatus in adult respiratory insufficiency associated with septicemia. Am Rev Respir Dis 116: 589-615

29. Strieter RM, Belperio JA, Keane MP (2002) Cytokines in innate host defense in the lung. J Clin Invest 109: 699-705.

30. Cheng DS, Han W, Chen SM, Sherrill TP, Chont M, et al (2007) Airway epithelium controls lung inflammation and injury through the NF-kappa B pathway. J Immunol 178: 6504-6513.

31. Mittal N, Sanyal SN (2011) In vivo effect of surfactant on inflammatory cytokines during endotoxin-induced lung injury in rodents. J Immunotoxicol 8: 274-283.

32. Fortis S, Speith PM, Lu WY, Parotto M, Haitsma JJ, et al (2012) Effects of anesthetic regimes on inflammatory responses in a rat model of acute lung injury. Intensive Care Med 38: 1548-1555.

33. Tang PS, Mura M, Seth R, Liu M (2008) Acute lung injury and cell death: how many ways can cells die? Am J Physiol Lung Cell Mol Physiol 294: L632-L641.

34. Magalhães CB, Riva DR, DePaula LJ, Brando-Lima A, Koatz VL, et al (2010) In vivo anti-inflammatory action of eugenol on lipopolysaccharide-induced lung injury. J Appl Physiol 108: 845-851.

35. Martin G, Bogdanowicz P, Domagala F, Ficheux H, Pujol JP (2003) Rhein inhibits interleukin-1 beta-induced activation of MEK/ERK pathway and DNA binding of NK-kappa B and AP-1 in chondrocytes cultured in hypoxia: a potential mechanism for its disease-modifying effect in osteoarthitis. Inflammation 27: 233-246.

36. Li HL, Chen HL, Li H, Zhang KL, Chen XY, et al (2005) Regulatory effects of emodin on NF-kappaB activation and inflammatory cytokine expression in RAW 264.7 macrophages. Int J Mol Med 16: 41-47.

37. Riedemann NC, Guo RF, Ward PA (2003) The enigma of sepsis. J Clin Invest 112: $460-467$

38. Li X, Su J, Cui X, Li Y, Barochia A, et al (2009) Can we predict the effects of NF-kappaB inhibition in sepsis? Studies with parthenolide and ethyl pyruvate. Expert Opin Investig Drugs 18: 1047-1060.

39. Zheng X, Yang D, Liu X, Wang N, Li B, et al (2010) Identification of a new anti-LPS agent, geniposide, from Gardenia jasminoides Ellis, and its ability of direct binding and neutralization of lipopolysaccharide in vitro and in vivo. Int Immunopharmacol 10: 1209-1219.

40. Nan YH, Bang JK, Shin SY (2009) Design of novel indolicidin-derived antimicrobial peptides with enhanced cell specificity and potent anti-inflammatory activity. Peptides 30: 832-838.

41. Lichtman AH, Leung D, Shelton CC, Saghatelian A, Hardouin C, et al (2004) Reversible inhibitors of fatty acid amide hydrolase that promote analgesia: evidence for an unprecedented combination of potency and selectivity. J Pharmacol Exp Ther 311: 441-448.

42. Shen HC, Hammock BD (2012) Discovery of inhibitors of soluble epoxide hydrolase: a target with multiple potential therapeutic indications. J Med Chem 55: 1789-1808. 
43. Tazi el M, Essadi I, M'rabti H, Touyar A, Errihani PH (2011) Systemic treatment and targeted therapy in patients with advanced hepatocellular carcinoma. N Am J Med Sci 3: 167-175.

44. Hoyle GW, Hoyle CI, Chen J, Chang W, Williams RW, et al (2010) Identification of triptolide, a natural diterpenoid compound, as an inhibitor of lung inflammation. Am J Physiol Lung Cell Mol Physiol 298: L830-L836.

45. Regueiro V, Moranta D, Campos MA, Margareto J, Garmendia J, et al (2009) Klebsiella pneumoniae increases the levels of Toll-like receptors 2 and 4 in human airway epithelial cells. Infect Immun 77: 714-724.

46. Villar J, Cabrera N, Casula M, Flores C, Valladares F, et al (2010) Mechanical ventilation modulates Toll-like receptor signaling pathway in a sepsis-induced lung injury model. Intensive Care Med 36: 1049-1057.

47. Villar J, Cabrera NE, Casula M, Flores C, Valladares F, et al (2010) Mechanical ventilation modulates TLR4 and IRAK-3 in a non-infectious, ventilator-induced lung injury model. Respir Res 11: 27.

48. Roger T, Froidevaux C, Le Roy D, Reymond MK, Chanson AL, et al (2009) Protection from lethal gram-negative bacterial sepsis by targeting Toll-like receptor 4. Proc Natl Acad Sci USA 106: 2348-2352.

49. Meduri GU, Headley S, Kohler G, Stentz F, Tolley E, et al (1995) Persistent elevation of inflammatory cytokines predicts a poor outcome in ARDS. Plasma
IL-1 beta and IL-6 levels are consistent and efficient predictors of outcome over time. Chest 107: 1062-1073.

50. Aggarwal A, Baker CS, Evans TW (2000) G-CSF and IL-8 but not GM-CSF correlates with severity of pulmonary neutrophilia in acute respiratory distress syndrome. Eur Respir J 15: 895-901.

51. Herrera MT, Toledo C, Valladares F, Muros M, Diaz-Flores L, et al (2003) Positive end-expiratory pressure modulates local and systemic inflammatory responses in a sepsis-induced lung injury model. Intensive Care Med 29: 13451353.

52. Tremblay L, Valenza F, Ribeiro SP, Li J, Slutsky AS (1997) Injurious ventilatory strategies increase cytokines and c-fos m-RNA expression in an isolated rat lung model. J Clin Invest 99: 944-952.

53. Remick DG, Bolgos GR, Siddiqui J, Shin J, Nemzek JA (2002) Six at six: interleukin- 6 measured $6 \mathrm{~h}$ after the initiation of sepsis predicts mortality over 3 days. Shock 17: 463-467.

54. Poynter ME, Irvin CG, Janssen-Heininger YM (2003) A prominent role for airway epithelial NF-kappa B activation in lipopolysaccharide-induced airway inflammation. J Immunol 170: 6257-6265.

55. Park GY, Christman JW (2006) Nuclear factor kappa B is a promising therapeutic target in inflammatory lung disease. Curr Drug Targets 7: 661-668. 